\title{
GAIA Level 2 Low Birth Weight
}

National Cancer Institute

\section{Source}

National Cancer Institute. GAIA Level 2 Low Birth Weight. NCI Thesaurus. Code C128726.

GAIA Level 2 Low Birth Weight is defined by either one of the following two criteria: first, a newborn infant is weighed within 24 hours of birth; either an electronic or a spring scale that is graduated to 50 grams is used; the scale is calibrated at least once a year, or more often if moved; the scale is tared to zero grams or $0.00 \mathrm{~kg}$; AND the birth weight recorded is less than 2500 grams; OR second, a birth weight is recorded as less than 2500 grams as assessed per the health care facility's standard operating procedure, which fulfills criteria 1 to 4 of diagnostic level of certainty two. 